\title{
SELECTION AND CHARACTERIZATION OF BRIVUDIN RESISTANT BOVINE HERPESVIRUS TYPE 5
}

\section{Mário Celso Sperotto Brum¹; Cyndia Mara Bezerra dos Santos² Rudi Weiblen $^{3}$; Eduardo Furtado Flores ${ }^{3 *}$}

${ }^{1}$ Programa de Pós-Graduação em Medicina Veterinária, Centro de Ciências Rurais, Universidade Federal de Santa Maria, Santa Maria, RS, Brasil; ${ }^{2}$ Curso de Medicina Veterinária, Centro de Ciências Rurais, Universidade Federal de Santa Maria, Santa Maria, RS, Brasil; ${ }^{3}$ Departamento de Medicina Veterinária Preventiva e Departamento de Microbiologia e Parasitologia, Universidade Federal de Santa Maria, Santa Maria, RS, Brasil.

Submitted: November 12, 2008; Returned to authors for corrections: June 23, 2009; Approved: August 22, 2009.

\begin{abstract}
Bovine herpesvirus type 5 (BoHV-5) is the agent of meningoencephalitis, an important disease of cattle in South America. The neuropathogenesis of BoHV-5 infection is poorly understood and most previous research focused on the role of envelope glicoproteins in neurovirulence. Thymidine kinase (TK) is a viral enzyme necessary for virus replication in neurons and, therefore, represents a potential target for virus attenuation. The selection and characterization of BoHV-5 variants resistant to the nucleoside analog brivudin (BVDU), which selects TK-defective viruses is here described. Several BVDU-resistant clones were obtained after multiple passages in tissue culture in the presence of BVDU and one clone (BoHV5/R-27) was further characterized. The selected clone replicated to similar titers and produced plaques with similar size and morphology to those of wild-type virus (SV507/99). The genetic stability of the resistant virus was demonstrated after ten passages in cell culture in the absence of the drug. Moreover, the drugresistant virus showed reduced virulence in a rabbit model: virus inoculation in four rabbits did not result in disease, in contrast with $75 \%$ morbidity (3/4) and 50\% mortality (2/2) among rabbits inoculated with the parental virus. These results demonstrate that BoHV-5 is sensitive to BVDU and that drug-resistant mutants can be readily selected upon BVDU treatment. BVDU-resistant mutants, likely defective in TK, retained their ability to replicate in tissue culture yet were attenuated for rabbits. This strategy to obtain TK-defective BoHV-5 may be useful to study the role of TK in BoHV-5 neuropathogenesis and for vaccine development.
\end{abstract}

Key words: BoHV-5, thymidine kinase, drug resistant, brivudin

\section{INTRODUCTION}

Bovine herpesvirus type $5(\mathrm{BoHV}-5)$ is the agent of necrotizing meningoencephalitis, but sporadically has been also isolated from cases of genital disease, abortions and systemic infection in calves (23). Unlike bovine herpesvirus type 1 (BoHV-1), BoHV-5 seems to have a more limited geographic distribution and has been frequently isolated from outbreaks of neurological disease in South American countries such as Brazil, Argentina and Uruguay (22, 25, 30). 
BoHV-5 belongs to the subfamily Alphaherpesvirinae, genus Varicellovirus (20). Its genome consists of a linear double stranded DNA molecule with approximately $138 \mathrm{~kb}$ in length $(9,20)$. The viral genome encodes around 70 different polypeptides, which include glycoproteins, structural, regulatory proteins and enzymes (9). Like all known herpesviruses, BoHV-5 encodes its own thymidine kinase (TK), which based on the homology with human herpes simplex virus (HSV) and BoHV-1, is an enzyme involved in the metabolism of deoxyribonucleotides in non-replicating cells $(9,24,26)$. The role of TK in the herpesvirus replication is to supply a pool of deoxyribonucleotides for viral DNA synthesis in non dividing cells such as neurons $(26,31)$. As TK is not required for virus replication in cell culture, its gene has been classified as non-essential. Nonetheless, TK activity is necessary for the full expression of virulence in vivo and its deletion from HSV-1, BoHV-1 and pseudorabies virus (PRV) genomes is associated with significant reduction in virulence $(1,3,16,27)$. Therefore, TK deletion has become an attractive target for gene manipulation of herpesviruses aiming to obtain attenuated viruses for vaccine use $(3,10,17,26,28)$.

The ability to establish latent infection seems not to be affected in TK-negative viruses, but its reactivation and subsequent replication are seriously impaired (26). The substrates for herpesvirus TK are deoxypyrimidine nucleosides and synthetic nucleoside analogs such as acyclovir (ACV), penciclovir (PCV), ganciclovir (GCV) and brivudin (BVDU) (18, 26, 31). Since BoHV-5 displays a marked neurotropism and its replication in the brain results in severe neurological signs and neuropathology, it is reasonable to assume that TK plays an important role in BoHV-5 neuropathogenesis.

BoHV-5 neuropathogenesis is not completely understood, yet multiple factors - host, viral and environmental - probably influence the production of clinical signs and neuropathology $(4,19,21,25)$. Most of the previous research to elucidate the pathogenesis of BoHV-5 focused on the role of envelope glicoproteins $(5-7,15)$ and very little has been done to determine the role of other viral products.
Different approaches have been developed to study the role of specific gene products on the biology of viruses. Chemical induced selection or mutagenesis is a very well established mean to produce variants defective in certain gene products, especially TK and DNA polymerase $(8,12,18)$. Brivudin (BVDU, E-5-bromovinyl-2'deoxyuridine) was first described in late 70's and it is commercially available in Europe to treat HSV-1 and varicella-zoster infections (8). Viruses expressing TKs resistant to BVDU activity have been selected and used to map TK active sites and to characterize its role in the biology of the virus in vivo and in vitro $(1,8,18)$.

In this study we describe the production and characterization of BoHV-5 mutants resistant to BVDU. The variants were readily obtained after treatment with BVDU, a nucleoside analog, and characterized in vitro and in vivo. For in vitro characterization, growth properties like plaque morphology, kinetics of replication, resistance to BVDU and stability were assayed. The neurovirulence of the BoHV-5 resistant virus was tested through inoculation of rabbits. Based on the characteristics of BoHV-1 or HSV BVDU-resistant viruses, our results suggests that BoHV-5 variants are likely deficient in TK. The data from these experiments also indicate that BoHV-5 BVDU resistant variants can be easily obtained upon exposure to BVDU; the mutation (s) leading to resistant phenotype is (are) stable and possibly present in the TK gene. Furthermore, this (these) mutation (s) confer (s) viral attenuation in the rabbit model.

\section{MATERIAL AND METHODS}

\section{Cells, viruses and chemical}

CRIB cells (cells resistant to infection with bovine viral diarrhea virus), a cell line derived from MDBK cells (13), were maintained in Minimal Essential Medium (MEM, Nutricell, Brazil), supplemented with $5 \%$ fetal bovine serum (Nutricell), and $1 \mathrm{x}$ antibiotics and antifungics (Gibco, USA). The virus strains used in this study were: BoHV-1 Cooper (wild-type TK) and IBRV(NG)dltkdlgC (a TK-defective recombinant strain) (14), provided by Dr. Fernando A. Osorio (University of 
Nebraska, NE, USA); and BoHV-5 SV507/99. The strain SV507/99 is a BoHV-5 isolated from an outbreak of meningoencephalits in cattle in Southern Brazil (9). This virus is highly virulent for calves and rabbits $(9,22,29)$, and was used as the parental strain to produce/select the resistant viruses. The brivudin BVDU (E-5-bromovinyl-2'deoxyuridine) was a generous gift from Dr. Erik De Clercq (Rega Institute for Medical Research, Katholieke Universiteit Leuven, Belgium). The chemical was diluted in ultrapure sterile water at a concentration of $2.5 \mathrm{mg} / \mathrm{mL}$.

\section{Cell citotoxicity assays}

The toxicity of BVDU for CRIB cells was evaluated by using the Trypan Blue assay (2). Briefly, different concentrations of BVDU were prepared in MEM with $0.5 \%$ fetal bovine serum and incubated in duplicate during $72 \mathrm{~h}$ in 6 well plates containing a preformed monolayer of CRIB cells. Then, the cells were trypsinized and stained with $0.4 \%$ of Trypan Blue, counted in a Neubauer chamber and the cell viability was calculated.

\section{Sensitivity of BoHV-5 to BVDU}

To demonstrate the activity and specificity of BVDU against BoHV-5 SV507/99 TK, an experiment comparing the activity of the drug against BoHV-1 Cooper strain and IBRV(NG)dltkdlgC was performed. CRIB cells cultivated in 6 well plates were inoculated (2000 tissue culture infectious dose - TCID $_{50}$ ) in duplicate with one of the three viruses and incubated with $1 \mu \mathrm{g} / \mathrm{mL}$ of BVDU (18). Seven two hours post infection, the cells were harvested by freezing at $-80^{\circ} \mathrm{C}$, clarified by centrifugation and the supernatant was titrated by limiting dilution. The titers were calculated using Reed \& Muench methodology and expressed in $\mathrm{TCID}_{50} / \mathrm{mL}$. To evaluate the sensitivity of BoHV-5 SV507/99 to different BVDU concentrations $(0,0.01,0.1,1,10,50,100$ and $200 \mu \mathrm{g} / \mathrm{mL}$ ), a dose-response assay was performed. Six well plates containing monolayers or CRIB cells were inoculated and adsorbed with 2000 TCID $_{50}$ of the virus during $1 \mathrm{~h}$, the monolayers were washed and MEM containing $0.5 \%$ of fetal bovine serum and crescent concentrations of BVDU were added in duplicate (two wells per each drug concentration) and incubated for $72 \mathrm{~h}$. Cultures were frozen at $-80^{\circ} \mathrm{C}$, clarified by centrifugation and the supernatants were titrated as described above.

\section{Isolation of BoHV-5 BVDU-resistant mutants}

The methodology described by Mittal \& Field (18) was used to obtain BoHV-5 BVDU-resistant viruses. Briefly, a 25 $\mathrm{cm}^{2}$ flask with a confluent monolayer of CRIB cells was inoculated with a m.o.i. (multiplicity of infection) of 1 and adsorbed for $1 \mathrm{~h}$. After adsorption, the inoculum was removed and the medium was replaced with $0.5 \%$ fetal bovine serum added of BVDU to $1 \mu \mathrm{g} / \mathrm{mL}$. The cultures were maintained until the cytophatic effect (CPE) reached 90\% of the monolayer. On the second round, the cells were infected with a m.o.i. of 10 as described above, and replaced with medium containing $10 \mu \mathrm{g} / \mathrm{mL}$ of BVDU. When the CPE reached $90 \%$, cells were frozen at $-80^{\circ} \mathrm{C}$, clarified by centrifugation and the supernatant was used to infect cells in a plaque assay. In this assay, individual plaques were subsequently picked, purified and amplified for further analysis. To confirm the resistant phenotype, isolated viruses were grown in the absence or presence of $10 \mu \mathrm{g} / \mathrm{mL}$ of BVDU and the supernatants collected at $72 \mathrm{~h}$ were titrated and the titers were compared.

\section{In vitro characterization of BoHV -5 resistant to BVDU}

To evaluate the growth characteristics of BoHV-5 BVDUresistant viruses, experiments to determine plaque morphology, kinetics of replication and stability were performed. Plaque morphology and one step growth curve were performed as described (3). To determine the stability of the resistant phenotype, ten blind passages of the BoHV-5 BVDU resistant clones were performed in CRIB cells, without the presence of BVDU. At the end, the supernatant from the first and tenth passages were used to infected cell cultures (2000 TCID $_{50} /$ well) in presence or absence of BVDU. Again, $48 \mathrm{~h}$ post-infection, the viruses were harvested and titrated as described above, and the resulting titers were compared. 


\section{Virulence in vivo}

The virulence of one BoHV-5 BVDU-resistant virus compared to the parental BoHV-5 strain was investigated in the rabbit model $(4,21)$. Briefly, animals were tranquilized (Zoletil@, Virbac, France) and inoculated with $1 \mathrm{~mL}$ of virus suspension containing approximately $10^{7.5} \mathrm{TCID}_{50}$ through the nephrine openings into the nasal cavity. The animals were monitored thereafter on a daily basis until day 21 post infection (pi). Animals that developed neurological disease were euthanized in extremis. All procedures of animal handling and experimentation were performed according to recommendations by the Brazilian Committee on Animal Experimentation (COBEA; law \#6.638 of 8th May 1979). The animal experiments were approved by an Institutional Ethics and Animal Welfare Committee (Comitê de Ética e Bem Estar Animal, Universidade Federal de Santa Maria, UFSM, approval \#44/2008; process \#23081.010078/2008-41).

\section{RESULTS}

\section{BVDU cell toxicity}

The toxicity of BVDU for CRIB cells was evaluated by morphological examination of cultures and by Trypan Blue assay. Concentrations of $1 \mu \mathrm{g} / \mathrm{mL}$ of the drug led to rounding and detachment of some cells. These alterations were more frequently observed with concentrations higher than $10 \mu \mathrm{g} / \mathrm{mL}$; doses of 100 and $250 \mu \mathrm{g} / \mathrm{mL}$ reduced dramatically the number of surviving cells. Cell viability tested by Trypan Blue assay confirmed the morphological examination and demonstrated that concentrations higher than $10 \mu \mathrm{g} / \mathrm{mL}$ were toxic and reduced the number of viable cells in more than $50 \%$ (data not shown). Similar results were obtained using the crystal violet assay described by Fernandes et al. (11) (data not shown).

\section{Sensitivity of BoHV-5 to BVDU}

The sensitivity of BoHV-5 to BVDU was determined in two experiments. First, the sensitivity of BoHV-5 TK to BVDU $(1 \mu \mathrm{g} / \mathrm{mL})$ was demonstrated by testing the SV507/99 strain in parallel with BoHV-1 Copper and IBRV(NG)dltkdlgC strains. Fig. 1A demonstrates the sensitivity of SV507/99 and
Cooper strains, known to have wild-type TKs, and the resistance of IBRV (NG)dltkdlgC, a well characterized TK deficient virus (14). When the SV507/99 was grown in presence of BVDU, the virus titer was reduced over two logs. A titer reduction was also observed in the Cooper strain, yet with a lower magnitude. The difference in the degree of reduction in titer (BoHV-1 versus BoHV-5) might indicate that BoHV-5 TK is more sensitive to BVDU than BoHV-1 TK. However more specific and detailed assay would be necessary to confirm the difference in BoHV-5 and BoHV-1 TK sensitivity. On the other hand, the growth of IBRV(NG)dltkdlgC was not affected by the presence of BVDU, demonstrating the specificity of the drug on TK activity.

In a dose-response experiment, it was possible to observe that SV507/99 was sensitive to concentrations higher than $0.01 \mu \mathrm{g} / \mathrm{mL}$ (Fig. 1B). Concentrations of 0.1 and $1 \mu \mathrm{g} / \mathrm{mL}$ reduced more than $50 \%$ of virus yield, and concentrations higher than $10 \mu \mathrm{g} / \mathrm{mL}$ resulted in lack of detection of infectious virus in the cell supernatant. Infectious virus could not be detected in cell supernatants in which the cultures were maintained with concentrations higher of $100 \mu \mathrm{g} / \mathrm{mL}$, yet some positive staining for virus antigens using imunoperoxidase assay was observed (not shown). This indicates that virus replication was not totally inhibited, but reduced to very low levels.

Taken together, these results showed that BoHV-5 replication in tissue culture is sensitive, in a dose-dependent manner, to BVDU. Based on the known mechanism of drug action, these results also indicate that this inhibition is due to the impairment of viral TK activity.

\section{Isolation and characterization of BoHV-5 BVDU-resistant mutants in vitro}

Isolation of viral plaques that were able to grow after two rounds of treatment with BVDU was readily achieved. At least eighteen individual plaques were selected and picked after agar overlay assay, using the virus harvested from the second round of BVDU treatment. After plaque purification and amplification, the BVDU-resistant phenotype (R) was 
confirmed by assaying the ability of replication in presence $(1 \mu \mathrm{g} / \mathrm{mL})$ or absence of BVDU, followed by virus titration of the supernatant. From 18 viral plaques isolated, at least 11 were shown to have a BVDU-resistant phenotype (not shown) and one, named BoHV-5/R-27, was chosen for further characterization.

A)

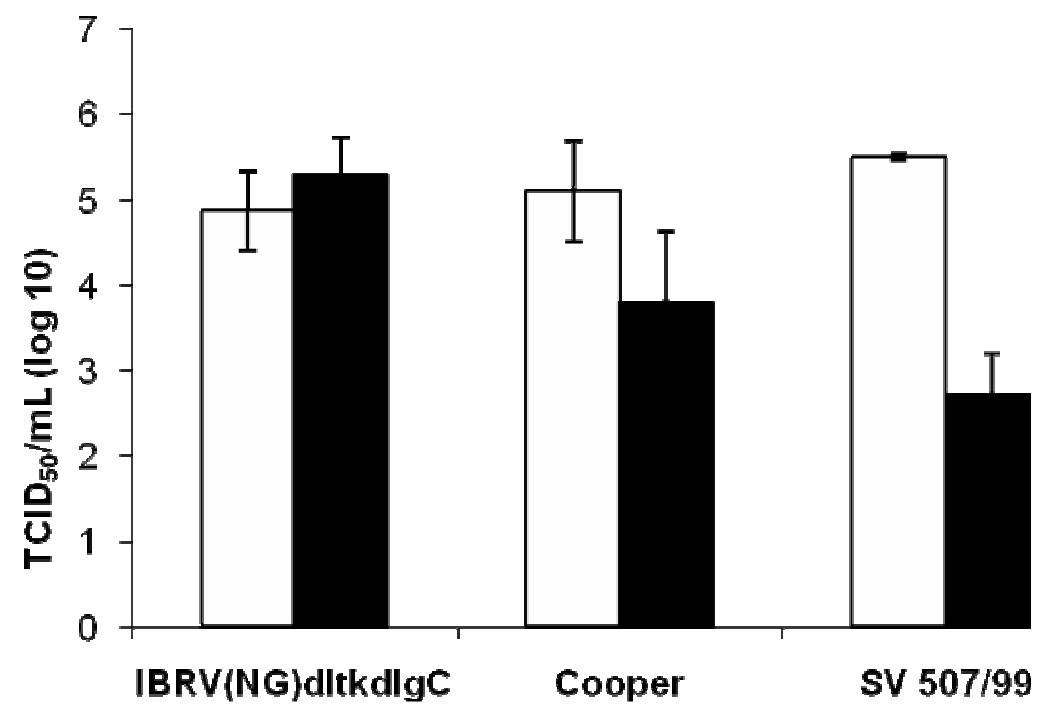

B)

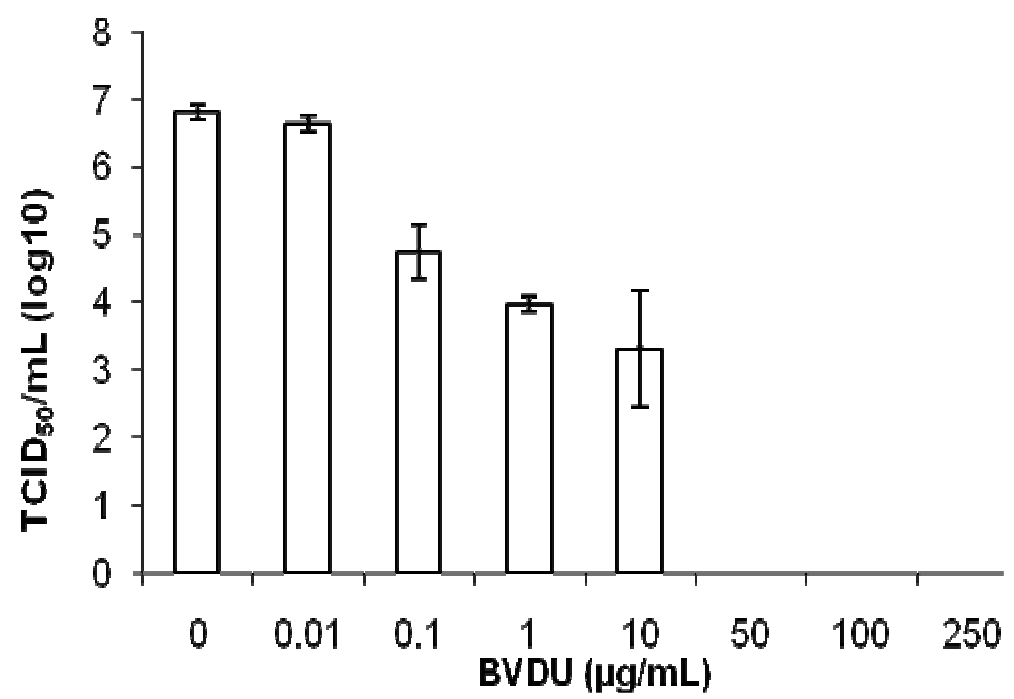

Figure 1. A) Effect of brivudin (BVDU) against bovine herpesvirus type 1 (BoHV-1 strains - IBRV(NG)dltkdlgC and Cooper) and bovine herpesvirus type 5 (BoHV-5 - SV507/99). All three viruses were grown in the absence ( $\square$ ) or presence ( $\square$ ) of BVDU (1 $\mu \mathrm{g} / \mathrm{mL}$ ) and, after $72 \mathrm{~h}$, the supernatants were harvested and titrated. Average of duplicates and standard deviations are shown. B) Dose-response experiment to evaluate the sensitivity of BoHV-5 to different concentrations of BVDU. SV507/99 wild-type was multiplied in the presence of different concentrations of BVDU $(0.01-250 \mu \mathrm{g} / \mathrm{mL})$ and the supernatant collected $72 \mathrm{~h}$ was titrated. Bars represent the average of duplicate and error bars represent standard deviation. 
Plaque morphology evaluated by plaque assay and staining with $0.35 \%$ of crystal violet demonstrated that both SV507/99 and BoHV-5/R-27 produced plaques with similar diameter and morphology (not shown). These results indicate that the resistant phenotype of this variant is not accompanied by altered capacity of cell-to-cell dissemination. The kinetics of replication in cell culture was evaluated using the parental virus (SV507/99) and the BVDU-resistant virus BoHV-5/R-27. Results demonstrated that the efficiency and kinetics of replication were not significantly affected (Fig. 2). Again, these results demonstrate that the acquisition of BVDU resistant phenotype by BoHV-5/R-27 was not associated with a reduced ability to replicate in tissue culture.

The genetic stability of the BoHV-5/R-27 resistant phenotype was evaluated after ten blind passages in cell culture in the absence of the drug. Viruses harvested at first and tenth passages were titrated and assayed, as described earlier, for the sensitivity to BVDU. Both passages of BoHV-5/R-27 (first and tenth) replicated to similar titers in the presence $(1 \mu \mathrm{g} / \mathrm{mL})$ or absence of BVDU, indicating that alterations in TK leading to resistance were stable and did not revert to the wild type phenotype.

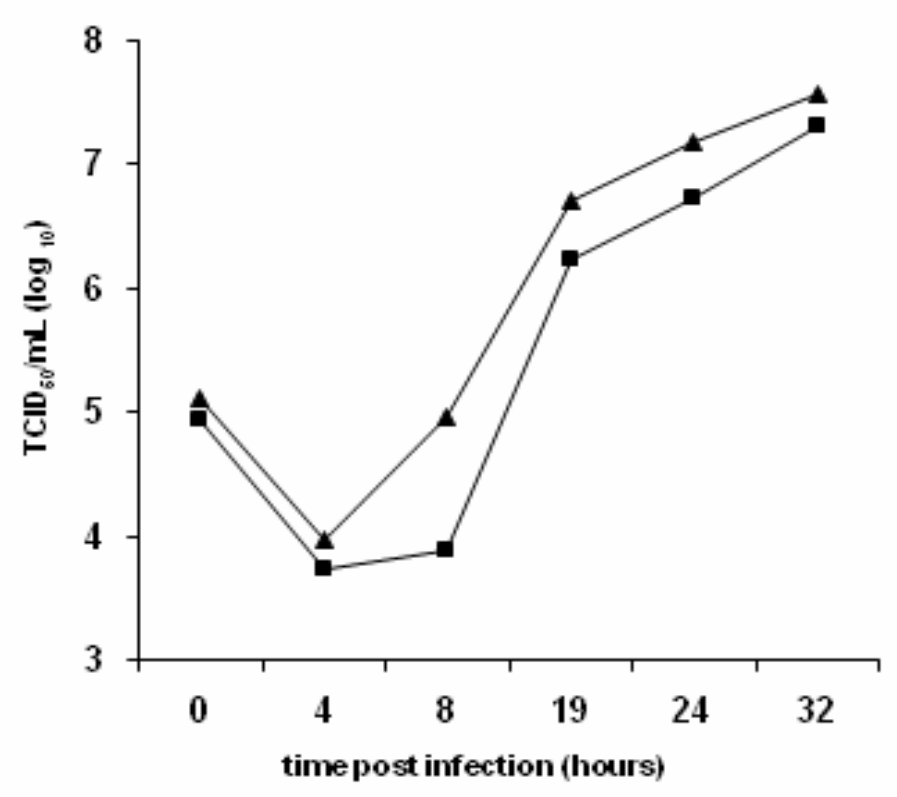

Figure 2. Kinetics of replication of bovine herpesvirus type 5 (BoHV-5) SV507/99 wild-type and BoHV-5/R-27 in tissue culture. CRIB cell monolayers were inoculated in duplicate with each virus SV507/99 ( $\mathbf{\Delta})$ or BoHV-5/R-27 (匹), harvested and titrated at different time-points post-inoculation.

\section{Virulence in vivo}

The virulence of BoHV-5/R-27 was tested in a rabbit model and compared to the parental virus. Inoculation of rabbits $(n=4)$ with the parental strain was followed of development of classical neurological signs of BoHV-5 infection in three animals, starting at day 6 pi. Two rabbits were euthanized in extremis and one recovered by day 12 pi. In contrast, rabbits $(n=4)$ inoculated with the BoHV-5/R-27 virus remained healthy and did not show any sign of neurological disease up to the last day of monitoring (day 21 pi). Virus replication in both groups was confirmed by seroconversion detected at 21 pi. These results demonstrated that the BVDUresistant BoHV-5 virus displays a reduced virulence for rabbits, while keeping its ability to replicate efficiently in cell culture. 


\section{DISCUSSION}

We herein demonstrated that BoHV-5 is sensitive to BVDU, as previously described for other alphaherpesviruses $(1,8,12,18)$. BVDU-resistant BoHV-5 variants were readily obtained by multiplicating the virus in tissue culture during two passages in the presence of the drug. Characterization of a BVDU-resistant viral clone demonstrated that the resistant phenotype is stable and that the acquisition of the resistance did not affect the ability of the virus to replicate in MDBK cells. Our results also demonstrate, for the first time, that TK activity is essential for the full expression of BoHV-5 neurovirulence: a BVDU-resistant mutant (likely defective in TK activity) was attenuated for rabbits. The methodology used for obtaining the BVDU-resistant virus was the same preconized by Mittal and Field (18). BVDU-resistant viruses obtained by this method likely presenting an impairment in TK activity - may be used for different purposes, including studies on the role of TK in neuropathogenesis and for vaccine development.

Bovine herpesvirus TK is not essential for virus replication in cell culture; TK-defective viruses do not present significant difference in virus growth in vitro but show reduced virulence in vivo $(3,17,27)$. The reduced virulence in vivo makes the TK an attractive target for attenuation towards vaccine production $(3,28)$. However, only partial deletions are allowed in TK coding region by genetic manipulation, because both flanking, essential genes (UL24 upstream and $\mathrm{gH}$ downstream) share coding regions or have regulatory regions inside TK ORF $(3,27,31)$. Thus, manipulation of BoHV-5 TK gene should be careful to avoid interfering with the expression of flanking genes. Since the role of TK in the biology and pathogenesis of BoHV-5 has not been studied, and genetic manipulation of the gene faces some technical problems, we took advantage of a well established method to produce BVDU-resistant mutants out of a highly virulent BoHV-5 strain $(1,18)$.

BVDU is a potent inhibitor of herpesvirus replication and its antiviral activity has been demonstrated against a wide variety of alpha and beta herpesviruses (8). The potency of antiviral activity is dependent of TK affinity for the drug and varies according to the virus species (8). BVDU is phosphorylated to both 5' monophosphate and 5'diphosphate forms by virally encoded TK, followed by phosphorylation by cellular kinases producing the active form of BVDU 5, triphosphate (BVDU-TP) $(8,12)$. The active form of BVDU has antiviral activity by competing with natural nucleoside substrate or through incorporation into the growing DNA chain, resulting in chain termination (8).

Herpesviruses expressing the enzyme TK resistant to BVDU naturally occur in a low frequency in the virus population $(\sim 0.1 \%)$ and can be readily selected in vitro by multiplying the virus in the presence of the drug (12). The drug resistant viruses usually have: i) a TK enzyme with an altered substrate specificity; ii) lack of expression of TK; or iii) decreased activity or production of small amounts of TK (8, 12). The most frequent mutations leading to a drug resistant phenotype are result of deletions, insertions or base substitutions, often in regions of repeated $\mathrm{G}, \mathrm{C}$ or occasionally A residues found in the TK coding region $(1,12,18)$. Mittal and Field (18) used a similar methodology to map BoHV-1 TK wild-type and demonstrated that mutations leading to a deficient TK phenotype were mostly associated with frameshift and chain termination mutations due to a nucleotide deletion. Also, the same kind of mutations were demonstrated to occur in HSV-1 TK BVDU resistant mutants (1).

Comparison of TK of BoHV-5 and BoHV-1 demonstrated that both genes share an homology of $83 \%$ at amino acid (aa) level and that BoHV-5 TK is 3 aa shorter than the BoHV-1 counterpart $(9,24)$. Most of the nucleotide sequence is conserved between these two viruses, including the putative enzyme active sites and the hot spots that are targets for mutations leading to the TK deficient phenotype $(9,24)$. We used similar methodology to that described by Mittal \& Field (18) and were able to isolate BoHV-5 clones resistant to BVDU. The selected viruses showed a marked resistance to BVDU, as ascertained by the capacity to replicate in presence of high concentrations of the drug (data not shown). The demonstration of reduced TK enzymatic activity or the 
determination of the genetic basis of the mutant phenotype were not attempted. Nevertheless, based on the similarity with other herpesviruses and already characterized BVDU resistant viruses, it is reasonable to assume that BoHV-5/R-27 has an impairment in TK activity.

Neurological disease associated with BoHV-5 infection results from invasion and widespread replication of the virus in the brain $(4,19,21,29)$. In this sense, it has been postulated that several gene products and factors may contribute for the neuropathogenesis of BoHV-5 $(5-7,22)$. The role of TK in the neuropathogenesis of this virus, however, has not been addressed to date. The association of TK function - as ascertained in other viral systems - and BoHV-5 pathogenesis indicate a possible and important role of TK in virus replication and dissemination in nervous tissue. Our results corroborate this hypothesis: inoculation of rabbits with BoHV-5/R-27 did not result in neurological disease, in contrast with neurological infection and disease observed among rabbits inoculated with wild-type virus. Thus, we demonstrated for the first time that BoHV-5 TK plays an essential role in the full expression of the neurovirulent phenotype in the rabbit model.

Functional characterization of herpesvirus genes has been classically performed by genetic manipulation of target genes, followed by in vivo and in vitro analysis of the resulting phenotype $(26,28)$. These studies can provide important insights for understanding the molecular basis of viral replication and pathogenesis; and may help the design of new strategies of control, including the development of safer and more effective vaccines. Herpesvirus vaccine candidates should be able to replicate to high titers in tissue culture; must be attenuated, genetically stable and should induce a strong immune response, and would preferentially have a serological marker to discriminate between vaccinated and infected animals $(26,28)$. In this case, the TK gene represents an attractive target for manipulation towards attenuation. However, an additional deletion would be necessary to introduce a serological marker; and the envelope glycoproteins $\mathrm{gE}, \mathrm{gC}, \mathrm{gI}$, or Us9 apparently represent adequate candidates for such $(15,16,26,28)$.
In summary, we demonstrated that BoHV-5 is sensitive to BVDU and were able to produce BVDU-resistant mutants. These mutants - likely defective in TK activity - retain their ability to grow in tissue culture, are genetically stable and showed a marked reduction in virulence in a rabbit model. Although these mutants need further genetic characterization before use as vaccine candidates, the attenuated phenotype is a highly desirable trait towards vaccine development and may be also explored to study the role of TK in the pathogenesis of BoHV-5 neurological infection.

\section{ACKNOWLEDGEMENTS}

This work is part of doctoral thesis of first author and was supported with funds from $\mathrm{CNPq}$ and FAPERGS. M.C.S. Brum is recipient of fellowship from CNPq (Brazilian Council for Research). E. F. Flores (301666/04-0) and R. Weiblen (301339/04-0) are recipients of CNPq scholarships. We are grateful to Dr. Erik De Clercq (Rega Institute for Medical Research, Katholieke Universiteit Leuven, Belgium) for providing the brivudin (BVDU) and M. S. e Silva and R. Dezengrini for helping with the animal experiments.

\section{REFERENCES}

1. Andrei, G.; Balzarini, J.; Fiten, P.; De Clercq, E.; Opdenakker, G.; Snoeck, R. (2005). Characterization of herpes simplex virus type 1 thymidine kinase mutants selected under a single round of high-dose brivudin. J. Virol. 79, 5863-5869.

2. Chowdhury, S.I. (1996). Construction and characterization of an attenuated bovine herpesvirus type 1 (BHV-1) recombinant virus. Vet. Microbiol. 52, 13-23.

3. Chowdhury, S.I.; Lee, B.J.; Mosier, D.; Sur, J.H.; Osorio, F.A.; Kennedy, G.; Weiss, M.L. (1997). Neuropathology of bovine herpesvirus type 5 (BHV-5) meningo-encephalitis in a rabbit seizure model. J. Comp. Pathol. 117, 295-310.

4. Chowdhury, S.I.; Lee, B.J.; Onderci, M.; Weiss, M.L.; Mosier, D. (2000). Neurovirulence of glycoprotein $\mathrm{C}(\mathrm{gC})$-deleted bovine herpesvirus type-5 (BHV-5) and BHV-5 expressing BHV-1 $\mathrm{gC}$ in a rabbit seizure model. J. Neurovirol. 6, 284-295.

5. Chowdhury, S.I.; Lee, B.J.; Ozkul, A.; Weiss, M.L. (2000). Bovine herpesvirus 5 glycoprotein $\mathrm{E}$ is important for neuroinvasiveness and 
neurovirulence in the olfactory pathway of the rabbit. J. Virol. 74, 20942106.

6. Chowdhury, S.I.; Onderci, M.; Bhattacharjee, P.S.; Al-Mubarak, A.; Weiss, M.L.; Zhou, Y. (2002). Bovine herpesvirus 5 (BHV-5) Us9 is essential for BHV-5 neuropathogenesis. J. Virol. 76, 3839-3851.

7. De Clercq, E. (2004). Discovery and development of BVDU (brivudin) as a therapeutic for the treatment of herpes zoster. Biochem. Pharmacol. 68, 2301-2315.

8. Delhon, G., Moraes, M.P.; Lu, Z.; Afonso, C.L.; Flores, E.F.; Weiblen, R.; Kutish, G.F.; Rock, D.L. (2003). Genome of bovine herpesvirus 5. J. Virol. 77, 10339-10347.

9. Engels, M.; Ackermann, M. (1996). Pathogenesis of ruminant herpesvirus infections. Vet. Microbiol. 53, 3-15.

10. Fernandes, M.J.B.; Limas, C.; Rossi, M.H.; Gonçales, E.; Simoni, I.C. (2005). Cytotoxicity of subfractions and compounds from Polymnia sonchifolia. Braz. J. Microbiol. 36, 338-341.

11. Field, H.J. (2001). Herpes simplex virus antiviral drug resistance-current trends and future prospects. J. Clin. Virol. 21, 261-269

12. Flores, E.F.; Donis, R.O. (1995). Isolation of a mutant MDBK cell line resistant to bovine viral diarrhea virus infection due to a block in viral entry. Virology. 208, 565-575.

13. Flores, E.F.; Osorio, F.A.; Zanella, E.L.; Kit, S.; Kit, M. (1993). Efficacy of a deletion mutant bovine herpesvirus-1 (BHV-1) vaccine that allows serologic differentiation of vaccinated from naturally infected animals. $J$. Vet. Diagn. Invest. 5, 534-540.

14. Franco, A.C; Hübner, S.O.; Oliveira, A.P.; Batista, H.B.C.R.; Roehe; P.M.; Rijsewijk, F.A.M. (2007). Construction and characterization of a bovine herpesvirus 5 mutant with a deletion of the gI, gE and US9 genes. Braz. J. Microbiol. 38, 667-673.

15. Kaashoek, M.J.; Rijsewijk, F.A.M.; Ruuls, R.C.; Keil, G.M.; Thiry, E.; Pastoret, P.P.; van Oirschot, J.T. (1998). Virulence, immunogenicity and reactivation of bovine herpesvirus 1 mutants with a deletion in the $\mathrm{gC}$, $\mathrm{gG}, \mathrm{gI}, \mathrm{gE}$, or in both the gI and gE gene. Vaccine. 16, 802-809.

16. Kaashoek, M.J.; van Engelenburg, F.A.; Moerman, A.; Gielkens, A.L.; Rijsewijk, F.A.M.; van Oirschot, J.T. (1996). Virulence and immunogenicity in calves of thymidine kinase- and glycoprotein Enegative bovine herpesvirus 1 mutants. Vet. Microbiol. 48, 143-153.

17. Mahy, B.W.J.; Kangro, H.O. (1996). Virology Methods Manual. Academic Press, San Diego, CA.

18. Mittal, S.K.; Field, H.J. (1989). Analysis of the bovine herpesvirus type 1 thymidine kinase (TK) gene from wild-type virus and TK-deficient mutants. J. Gen. Virol. 70, 901-918.

19. Perez, S.E.; Bretschneider, G.; Leunda, M.R.; Osorio, F.A.; Flores, E.F.; Odeon, A.C. (2002). Primary infection, latency, and reactivation of bovine herpesvirus type 5 in the bovine nervous system. Vet. Pathol. 39, 437-444.

20. Roizmann, B., Desrosiers, R.C.; Fleckenstein, B.; Lopez, C.; Minson, A.C.; Studdert, M.J. (1992). The family Herpesviridae: an update. The Herpesvirus Study Group of the International Committee on Taxonomy of Viruses. Arch. Virol. 123, 425-449.

21. Silva, A.M.; Flores, E.F.; Weiblen, R.; Canto, M.C.; Irigoyen, L.F.; Roehe, P.M.; Sousa, R.S. (1999). Pathogenesis of meningoencephalitis in rabbits by bovine herpesvirus type-5 (BHV-5). Revista de Microbiologia. 30, 22-31.

22. Silva, M.S.; Brum, M.C.S.; Loreto, E.L.; Weiblen, R.; Flores, E.F. (2007). Molecular and antigenic characterization of Brazilian bovine herpesvirus type 1 isolates recovered from the brain of cattle with neurological disease. Virus Res. 129, 191-199.

23. Silva, M.S.; Brum, M.C.S.; Weiblen, R.; Flores, E.F. (2007). Identificação e diferenciação de herpesvírus bovino tipos 1 e 5 isolados de amostras clínicas no Centro-Sul do Brasil, Argentina e Uruguai (19872006). Pesq. Vet. Bras. 27, 403-408.

24. Smith, G.A.; Young, P.L.; Mattick, J.S. (1991). Nucleotide and amino acid sequence analysis of the thymidine kinase gene of a bovine encephalitis herpesvirus. Arch. Virol. 119, 199-210.

25. Suarez-Heinlein, A.; Metzler, A.E.; Weiblen, R.; Berrios, P.; Schudel, A.A.; Rodriguez, M. (1993). Molecular characterization of South American bovine herpesvirus-1 isolates with monoclonal antibodies and SDS-PAGE. Zentralbl. Veterinarmed. B 40, 125-130.

26. Tikoo, S.K.; Campos, M.; Babiuk, L.A. (1995). Bovine herpesvirus 1 (BHV-1): biology, pathogenesis, and control. Adv. Virus. Res. 45, 191223.

27. van Engelenburg, F.A.; Kaashoek, M.J.; Rijsewijk, F.A.M.; van den Burg, L.; Moerman, A.; Gielkens, A.L.; van Oirschot, J.T. (1994). A glycoprotein E deletion mutant of bovine herpesvirus 1 is avirulent in calves. J. Gen. Virol. 75, 2311-2318.

28. van Oirschot, J. T. (1999). Diva vaccines that reduce virus transmission. J. Biotechnol. 73, 195-205.

29. Vogel, F.S.F.; Caron, L.; Flores, E.F.; Weiblen, R.; Winkelmann, E.R.; Mayer, S.V.; Bastos, R.G. (2003). Distribution of bovine herpesvirus type 5 DNA in the central nervous systems of latently, experimentally infected calves. J. Clin. Microbiol. 41, 4512-4520.

30. Weiblen, R.; Barros, C.S.L.; Canabarro, T.F.; Flores, I.E. (1989). Bovine meningoencephalitis from IBR virus. Vet. Rec. 124, 666-667.

Weinmaster, G.A., Misra, V.; McGuire, R.; Babiuk, L.A.; De Clercq, E. (1982). Bovid herpesvirus type-1 (infectious bovine rhinotracheitis virus)-induced thymidine kinase. Virology. 118, 191-201. 